doi: 10.12957 / childphilo.2019.42479

\title{
peter pan: el líder y sus seguidores. una experiencia de filosofía con niños
}

esther charabati ${ }^{1}$

universidad nacional autónoma de méxico, mexico orcid id: https:/ / orcid.org/0000-0001-8608-7925

\section{resumen}

La filosofía y la literatura están unidas por fuertes lazos que se evidencian en ambas disciplinas: son muchos los textos literarios y filosóficos en los que se pueden rastrear las influencias recíprocas. En esta experiencia de filosofía con niños se partió de una obra clásica, Peter Pan, para motivar a alumnos de primaria. Los objetivos fueron a) desarrollar el pensamiento crítico y ético a través de la problematización de la vida escolar, b) desarrollar habilidades de análisis, síntesis, inferencia, argumentación, cuestionamiento y pensamiento creativo, c) que los alumnos relacionaran sus experiencias cotidianas con las situaciones que se plantean en la historia. Peter Pan retrata a un tipo de persona muy popular en nuestra época: el líder. Peter es inteligente y simpático, posee la valentía y el carisma suficiente para seducir a los niños perdidos, a los pieles rojas y a Wendy y sus hermanos. Su imaginación y pasión por la aventura lo vuelven aún más atractivo. Peter también encarna defectos que reconocemos en numerosos líderes: vanidad, egoísmo y falta de responsabilidad. Para ejercer el poder cuenta con la sumisión de los niños perdidos. Si en el texto ambas conductas nos parecen naturales, al identificarlas en la vida cotidiana de nuestras escuelas sólo podemos nombrarlas con palabras como bullying, matonismo, agresión, víctimas... Esta experiencia mostró que las obras literarias pueden servir como detonador para la reflexión y el debate, tanto de la vida escolar como de dilemas de la vida cotidiana aportados por los alumnos; permitió el cuestionamiento sobre las relaciones entre pares y la argumentación de sus posturas; también fue posible apreciar las posibilidades que abre tener un espacio para potenciar la imaginación. En el caso de los docentes, pudieron conocer y comprobar la función problematizadora de las preguntas, aunque sólo algunos aprendieron a formularlas. Una escasa formación en pensamiento crítico disminuye su capacidad para implementar estrategias que contribuyan al desarrollo de las habilidades mencionadas.

palabras clave: educación; ética; bullying; literatura.

\section{peter pan: the leader and his followers. an experience of philosophy with children}

\begin{abstract}
Philosophy and literature are linked by strong ties that are evident in both disciplines: there are numerous literary and philosophical works in which reciprocal influences can be traced. This philosophical experience with children started from a classic work, Peter Pan, to motivate elementary school students. The goals were a) to develop critical thinking skills and ethical problematization around school issues; b) to develop analysis, synthesis, inferring, debate, questioning, and creative thinking skills; and c) for students to make connections between their daily experiences and the situations discussed in the story. Peter Pan portrays a popular kind of character of our times: the leader. Peter is smart and friendly, possesses enough courage and charisma to entice lost children, the Red Skins, and Wendy and her siblings. His imagination and passion for adventure make him even more appealing. Peter also embodies flaws
\end{abstract}

${ }^{1}$ E-mail: eticacotidiana@gmail.com 
peter pan: el líder y sus seguidores. una experiencia de filosofía con niños

commonly seen in numerous leaders: vanity, selfishness, and lack of responsibility. To exert control he relies on the submission of lost children. While both behaviors may seem natural to us in the story, in real life at school we would label them with words like bullying, abuse, aggression, victims... This experience showed that literary works can trigger deep thinking and debate in students that apply to dilemmas in both school and everyday life; it prompted questioning regarding relationships and points of view; it was also possible to appreciate the possibilities that this space opened to encourage imagination. Educators could witness and see evidence of the power of questioning even though only a few of them had learned these skills. Limited background in critical thinking reduces the ability to implement strategies that contribute to the growth of the above mentioned skills.

keywords: education; ethics; bullying; literature.

\section{peter pan: o líder e seus seguidores. uma experiência de filosofia com crianças}

\section{resumo}

A filosofia e a literature estão unidas por fortes laços que se evidenciam em ambas disciplinas: são muitos os textos literários e filosóficos nos quais se pode rastrear as influências recíprocas. Nesta experiência de filocosia com crianças, se partiu de uma obra clássica, Peter Pan, para motivar alunos da educação infantil. Os objetivos eram: a) desenvolver o pensamento crítico e ético através da problematização da vida escolar; b) desenvolver habilidades de análise, síntese, inferência, argumentação, questionamento e pensamento criativo; c) que os alunos relacionassem suas experiências cotidianas com as situações que surgem na história. Peter Pan retrata um arquétipo muito popular de nosso tempo: o líder. Peter é inteligente e simpático, possui a valentia e o carisma suficientes para seduzir os meninos perdidos, aos pele-vermelhas e a Wendy e seus irmãos. Sua imaginação e paixão pela aventura fazem dele ainda mais atraente. Peter também encarna defeitos que reconhecemos em muitos líderes: vaidade, egoísmo e falta de responsabilidade. Para exercer poder, conta com a submissão dos meninos perdidos. Se no texto ambas condutas nos parecem naturais, ao identificá-las na vida cotidiana de nossas escolas, só podemos nomeálas com palavras como bullying, abuso, agressão, vítimas... Esta experiência mostrou que as obras literárias podem servir como gatilho para a reflexão e o debate, tanto da vida escolar como sobre dilemas da vida cotidiana trazidos pelos alunos; permitiu o questionamento sobre as relações entre os pares e a discussão sobre suas posturas; também foi possível apreciar as possibilidades que um espaço para potencializar a imaginação abre. Quanto aos professores, puderam conhecer e comprovar a função problematizadora das perguntas, ainda que só alguns tenham aprendido a formulá-las. Uma formação escassa em pensamento crítico diminue sua capacidade para implementar estratégias que contribuam para o desenvolvimento das habilidades mencionadas.

palavras-chave: educação; ética; bullying; literatura. 
peter pan: el líder y sus seguidores. una experiencia de filosofía con niños

Situada en ese país mágico, más allá de la realidad virtual de nuestros dispositivos, Peter Pan and Wendy ${ }^{2}$-la célebre novela de Barrie- crea una realidad alterna con personajes extrañamente parecidos a los jóvenes que se sumergen en su lectura: se trata de niños, niñas, adultos, indios y piratas que viven situaciones similares a las que los niños del siglo XX enfrentan cotidianamente y ante las que reaccionan de maneras parecidas. La novela se sitúa en una de las etapas más difíciles de la vida: aquella en la que, lejos de la casa y la familia, aprendemos a convivir con nuestros pares, a integrarnos en los grupos y a hacer amigos.

La hora del recreo brinda al observador un panorama sugerente: varios grupitos de niños o de niñas, algunos mixtos, a menudo organizados en torno a un líder que lleva la voz cantante. La mayoría parecen contentos: pertenecer a un grupo los salva de la soledad y del estigma, y disminuye su sensación de vulnerabilidad. Muchos de esos grupos están encabezados por un líder carismático y astuto que sabe ganarse la admiración, obediencia y fidelidad de los demás niños ofreciéndoles aventuras -reales o ficticias- y protección. Y más de uno de los que le aplauden está en busca de un líder que le dé sentido a su vida, ratifique su aceptación social y se haga cargo de él en esa tierra de nadie formada por recreos, pasillos, salida...

Los invito a mirar desde este ángulo la novela de Barrie. Las características de los niños perdidos los convierten en la pandilla perfecta de Peter Pan: Avispado es alegre y complaciente, Presuntuoso es ingenioso y presumido, Rizos asume la culpa de todo aunque no la tenga, Lelo es humilde y dulce, los gemelos son inseguros y siempre están en actitud de disculpa.

\section{intimidar para dominar}

Para formar parte de la pandilla de Peter hay que respetar una prohibición tácita: oponerse a sus deseos o decisiones. Si bien los líderes -de cualquier tipo- a menudo

\footnotetext{
${ }^{2}$ A partir de ahora, utilizaremos el título común a las ediciones en castellano: Peter Pan.
} 
peter pan: el líder y sus seguidores. una experiencia de filosofía con niños

exigen renuncias, cada uno tiene sus peculiaridades. En este caso la inconciencia, pues Peter no distingue entre fantasía y realidad. Los opíparos banquetes que ofrece a sus amigos a veces son reales, pero en otras sólo son imaginarios. Si alguno de ellos se atreve a protestar, Peter les pega en los nudillos: se sabe poderoso y suele imponer su voluntad con violencia.

La pertenencia a un grupo implica, por un lado, amistad, proyectos compartidos, solidaridad; por otro, supone inevitablemente fricciones, conflictos, temores y dificultades. (Skliar, 2017, p.71) El problema en las escuelas -que no es nuevo, pero se ha recrudecido- es cuando la relación de poder deriva en la intimidación creando víctimas, verdugos, testigos y mucho sufrimiento. Quisimos abordar este tema con los niños ${ }^{3}$ desde una perspectiva alejada de advertencias y amenazas, para iniciar un diálogo filosófico y pasar las conductas de líderes y seguidores por el cedazo de la experiencia; el material elegido fue el libro Peter Pan. ${ }^{4}$ La idea es cruzar miradas: que los niños escuchen las opiniones de sus compañeros, las propias y las del profesor, que éste formule preguntas pertinentes que generen reflexiones y nuevas preguntas, de manera que todos se sientan interpelados en un tema que quizá no han querido analizar y de pronto se vuelve impostergable. Como dice Kohan en una entrevista con Álvarez (2015, p. 203)

${ }^{3}$ Esta experiencia se describe en el último apartado.

${ }^{4}$ Distintos autores han hablado de la pertinencia de utilizar cuentos "clásicos" o conocidos para provocar reflexiones filosóficas en los niños: tomo las siguientes citas, de la magnífica tesis de Johanna Hawken. Philosopher avec les enfants: enquête théorique et expérimentale sur une pratique de l'ouverture d'esprit.

“Usar una lectura en voz alta para comenzar una discusión filosófica resuelve el problema de iniciación de una manera ingeniosa. (...) Como la historia ha involucrado a los niños, naturalmente intentan resolver el problema que planteamos. Nuestra creencia es que este proceso estimulará una investigación genuina por parte de los niños sobre el problema o el enigma que presentamos porque es un problema que surge directamente de la historia que se ha leído." (Wartenberg, citado por Hawken, 2016, p.359). (La traducción es mía).

“Las referencias literarias, de alguna manera, ponen el problema a buena distancia: entre la excesiva cercanía de la experiencia personal que impide el retroceso y la reflexión, y la excesiva lejanía del concepto, mismas que impiden la implicación y el involucramiento en el pensamiento." (Chirouter, citado por Hawken, 2016, p.362). (La traducción es mía).

“Todas las grandes historias de la humanidad tienen la capacidad de interpelar las preocupaciones y las necesidades de cualquier persona en las diversas etapas del desarrollo. Son polisémicas, es decir, poseen pliegues y niveles de significación de los que nos hacemos conscientes a medida que crecemos en experiencia y clarividencia. (...) Ofrecen metáforas de nuestras vidas." (Fisher, citado por Hawken, 2016, p.366) (La traducción es mía). 
(...) viste este momento de las preguntas, de ver el mundo como si fuera la primera vez o pensar el mundo como si fuera la primera vez, pensar la vida de manera más inmediata y espontánea. Un niño o una niña está en cierto sentido comenzando a vivir, entonces esa pregunta por cómo debe vivir está más a flor de piel.

Cuando les pedimos a los niños y a las niñas que explicaran las razones del comportamiento de Peter Pan en la escena mencionada, la mayoría respondió que al no haber tenido una madre que lo educara, no sabía cómo tratar a la gente. En cambio, atribuían la actitud sumisa de los niños perdidos no a la falta de educación, sino al miedo. Más que juzgar a los protagonistas -en ese caso probablemente hubieran hablado de crueldad, de egoísmo y de cobardía- los alumnos intentaban explicar sus conductas en los mismos términos en los que explican las propias. No nos extrañó que trataran de justificar a Peter Pan -el "héroe" de la novela"-, en cambio, el hecho de que el miedo les pareciera una razón legítima para la sumisión, nos obligó a preguntarnos y a preguntarles por las amenazas que viven en el grupo de pares, para identificarlas $\mathrm{y}$, en lo posible, desmitificarlas. Las preguntas son diversas, algunas más interesantes que otras, algunas con más potencialidad para la discusión pero, como afirma Maulini, las preguntas de los niños son sorprendentes, incesantes y obstinadas. (1998, p.14)

Por otro lado, fue interesante que reconocieran el papel de la familia particularmente el de la madre- en el desarrollo de las capacidades del individuo. Intuyen lo que advierte Philippe Meirieu: el niño necesita ser acogido: “Necesita que haya adultos que le ayuden a estabilizar progresivamente las capacidades mentales que ayudarán a vivir en el mundo (...) la actitud de los progenitores, desde el primer día, es determinante" (1998, p.23).

La ficción ofrece la cercanía que permite empatizar sin sentirse amenazado y la distancia que brinda el espacio para el juicio y la reflexión. En esta experiencia, la identificación con los personajes no tiene como objetivo la proyección de sentimientos -aunque siempre afloran-, sino detonar la reflexión. Las buenas obras literarias nos confrontan a nuestra humanidad, por lo que el niño se posiciona frente a preocupaciones humanas y logra descentrarse de su propia vida. “La literatura -como el cine y otras experiencias- presentan mundos que autorizan una mayor manipulación 
peter pan: el líder y sus seguidores. una experiencia de filosofía con niños

de las ideas y de las situaciones, y tienen una forma especulativa superior" (Hawken, 2016, p.394).

\section{que otro piense por mí}

Uno de los problemas que surgen en los grupos en los que uno solo detenta el poder es la dependencia de los seguidores: siempre están a la espera de la decisión de su líder, a quien suelen respetar y admirar. La ausencia de éste provoca ansiedad y confusión, como lo muestra la escena en que Avispado se ve perseguido por un grupo de lobos con la lengua colgando. El niño, asustado, pide auxilio a los demás. La pregunta a coro de éstos es: “¿Qué podemos hacer?”, “QQué haría Peter Pan?” y la respuesta, también a coro, es “Peter Pan los miraría por entre sus piernas" (Barrie, 2002, p.66). Actúan de acuerdo a esa idea prestada y, por una de esas felices casualidades que a veces nos brinda la literatura -y también la realidad-, los lobos, asustados, huyen.

Esta escena nos lleva a analizar la reacción de los niños perdidos ante el peligro y su falta de iniciativa. Los alumnos, al analizar esta escena, se dividieron ante las distintas opciones que se les ofrecían: a) a los niños perdidos les da flojera pensar, b) creen ciegamente en lo que les dice Peter Pan, c) cuando la gente está asustada no se le ocurre nada, d) como Peter siempre ha pensado por ellos, no han aprendido a decidir por sí mismos, e) como no han ido a la escuela, no tienen ideas propias. Cada una de estas respuestas puede ser asociada a creencias y a autores que han abordado la problemática, pero en el debate no aparecen discursos de autoridad. El maestro-guía tiene que reprimir su deseo de explayarse sobre éstas y ocuparse de que los planteamientos se conviertan en puntos de partida: ¿por qué a alguien le daría flojera pensar? ¿Ustedes se cansan cuando piensan? ¿Cómo se aprende a decidir? ¿Las personas que no fueron a la escuela no tienen ideas propias? ¿Por qué habría que tener ideas propias?

A los alumnos les resulta novedosa la idea de que a veces en los grupos de amigos todos se recargan en el líder y dejan en sus manos las decisiones, la organización y la responsabilidad. Hasta ese momento, sus intervenciones atribuían 
esta dependencia a una forma de ser y de actuar del líder, que le brinda satisfacción; no la veían como una forma de abuso ni se sentían comprometidos con las acciones que emprendían. Tampoco habían pensado que esa relación los debilitaba.

Estas experiencias de pensamiento que despiertan dudas a partir de una situación banal, atraen y exigen la atención de los alumnos, quienes se ven obligados a conceptualizar las alternativas, a argumentar su postura y a problematizar (Tozzi,1997); a imaginar el mundo de otra manera. Cada una de las opciones de la encuesta abre la posibilidad de profundizar en la relación causa-efecto. Por ejemplo, la opción $d$, que plantea que no están acostumbrados a pensar por sí mismos porque otro piensa por ellos, implica una serie de cuestionamientos: si dejo que otros piensen por mí, ¿dependo de ellos para cada decisión? Si otros piensan por mí, ¿estaré tomando las mejores decisiones para mí o para ellos? También habrá que preguntarse por los límites de la aseveración: ¿Cómo saber si estoy dejando que piensen por mí o si realmente estoy de acuerdo? A medida que se profundiza, los niños van generando nuevas ideas y analizando su validez.

Cada una de las respuestas a la encuesta es una hipótesis de trabajo, una puerta al pensamiento divergente y a la búsqueda de alternativas; permiten llevar las ideas hasta su límite y desarrollar tanto el espíritu crítico como la imaginación (Hawken, 2016, p.397). Para Brénifier, el término "hipótesis" instaura cierto distanciamiento de las ideas que uno tiene; a lo largo, del debate, se van convirtiendo en instrumentos de trabajo y se van modificando. (Citado en Hawken, 2016, p. 301)

\section{“¿no soy una maravilla?"}

Los tres hermanos, Wendy, Juan y Miguel, han volado hasta el País de Nunca Jamás convencidos de que sería la mejor aventura de su vida. Lo que no sabían era lo importante que resultaba para Peter ser admirado, incluso más que cuidar a sus amigos. Cuando Miguel, muerto de sueño, se cae a la mitad del vuelo, Wendy le pide a gritos a Peter que lo salve. Así lo describe Barrie:

Peter se zambullía en el aire y cogía a Miguel, justo antes de que llegara al mar, y era encantador el modo de hacerlo: siempre esperaba hasta el 
peter pan: el líder y sus seguidores. una experiencia de filosofía con niños

último instante y parecía que le interesaba más demostrar su habilidad que salvar una vida humana". (Barrie, 2002, p.46)

Peter Pan está tan seguro de sí mismo que no mide el peligro y constantemente se pone en riesgo; al hacerlo, arriesga a los demás. En otra escena, imita la voz del Capitán Garfio para que los piratas liberen a la princesa Tigridia, pero se cree tan genial que, en lugar de ponerse a salvo rápidamente, lo sigue imitando... hasta que él y Wendy son descubiertos y están a punto de morir. Al salvarse, “Toda temblorosa, Wendy hubiera querido alejarse nadando, pero Peter Pan no se movía. También él temblaba de emoción, lleno de ideas orgullosas. -¿No soy una maravilla? ¿No soy una maravilla?" (Barrie, 2002, p.92).

Es cierto que el narcisismo es un rasgo adolescente -Peter tiene doce años-, sin embargo, parece estar muy acentuado en nuestro protagonista, quien no sólo expone a sus amigos, sino que ni siquiera registra sus temores y los riesgos que corren, fascinado como está por su propia persona y sus propios logros.

Al reflexionar sobre estas escenas con los alumnos, el debate se centró en la responsabilidad colectiva frente a las conductas del líder: ¿Peter Pan actúa así porque nadie le pone límites y todos lo obedecen o su conducta es independiente de la actitud de los demás? ¿Su inmensa fantasía lo ha hecho creer que no le puede pasar nada o son los niños con su inmensa admiración quienes le han hecho pensar que es invencible? ¿Alguien le ha pedido que cambie? ¿No son los amigos los que nos ayudan a crecer? Las respuestas de los alumnos fueron diversas y el debate, acalorado: eran pocos los alumnos dispuestos a reconocer la obediencia -a veces absoluta- al líder. Los líderes, en su mayoría, negaron que ésa fuera la relación que se establece en los grupos, afirmaron no identificarse con la personalidad tan impositiva de Peter. Sin embargo, más de un alumno que se sentía excluido atribuyó al líder de su clase las características de Peter. El clima de respeto y cordialidad establecido en esta actividad permitió que el grupo se mantuviera en el nivel del diálogo, aunque no se buscaba el acuerdo: cuando hubo divergencias, como en este caso, el propósito era ahondar en ellas, reconocer la diferencia y el derecho a disentir. 
En éste, como en otros momentos "de riesgo", hubo que resistir a la tentación de dar una clase de moral. También a la tentación de crear una sesión terapéutica: la idea no es resolver los problemas personales de los niños con la ayuda del grupo, sino que cada uno desarrolle los pensamientos que necesita para su vida; el grupo está para testimoniar de la solidez y legitimidad de sus ideas. En otras palabras, como señala Agratti (2016, p. 143)

La experiencia del filosofar en la polifonía del aula nos acerca las cosas desconocidas con una actitud de apertura, con la pregunta que interpela y que hace emerger la multiplicidad de sentidos que ellas guardan. Un pensamiento que es uno y es muchos a la vez y que, por lo mismo, resulta enriquecido y único dejando en cada uno de los participantes del encuentro caminos para seguir problematizando personalmente aquello que los ha conmovido. Así nos enfrenta a la novedad de un saber que no busca apropiarse del mundo sino que quiere constituirse conforme a su particular manera de atravesar el terreno de la incertidumbre.

\section{valientes y narcisistas}

Si Peter Pan sólo fuera un niño caprichoso y egoísta, dedicado a alabarse a sí mismo, "- ¿Por qué no me vitoreáis?" (Barrie, 2002, p.69)- difícilmente tendría seguidores, por muy aventurero que fuera. Pero Peter, además de ser valiente, se preocupa por sus amigos y se arriesga por ellos, como lo hizo para salvar a la princesa india. A diferencia de Garfio, un hombre terrible obsesionado con la venganza y con su imagen (el buen tono), que trata a sus piratas como perros y ellos, por temor, lo obedecen como perros, los niños están con Peter Pan por afecto y porque se sienten protegidos por él. En ambos casos estamos ante líderes valientes y narcisistas, pero el primero, adulto y amargado, retiene a sus hombres contra su voluntad, y el segundo es un adolescente vital, alegre, a quienes los niños siguen por amistad y gratitud. Este tema también se presta a reflexión, no sólo para analizar distintos tipos de relaciones, sino porque estas situaciones permiten poner en conflicto la idea de que las cosas son buenas o malas, es decir, de que la realidad es simple y se la puede capturar en una palabra: "Líder" es un concepto del que hay que despegar muchas etiquetas que sólo le corresponden en determinados casos, por lo que, para superar los prejuicios, es necesario analizar los 
peter pan: el líder y sus seguidores. una experiencia de filosofía con niños

casos particulares. Hablamos de etiquetas como "positivo", "negativo", autoritario", "generoso”, " inteligente”, " abusador", “conciliador”, “violento”...

\section{cuando uno habla, los demás callan}

El hecho de que sean amigos no impide que Peter Pan se crea merecedor de todos los honores y se sienta superior a los demás, tal como lo refiere Barrie (2002, p. 107)

Siempre que decía 'Peter Pan ha hablado', quería decir que los demás debían callarse, y los indios lo aceptaban humildemente de él; pero no eran tan respetuosos con los otros niños, a los que consideraban como seres vulgares. Les decían '¿Qué tal? y cosas por el estilo, lo que molestaba a los pequeños, aunque a Peter Pan le parecía muy justa esta diferenciación.

El debate sobre esta escena llevó a las distinciones que los maestros, los padres y otros alumnos suelen hacer entre los niños. Si bien había un consenso respecto a la condición de igualdad -nadie ponía en duda que todos somos iguales- y un enojo por las diferenciaciones y preferencias, algunos protestaban ante una actitud que consideraban injusta, mientras que otros pensaban que "no valía la pena" pelear por ello. Un "líder" fue duramente criticado por preferir a unos y excluir a otros, y él se defendió con el argumento de que "cada uno puede elegir a sus amigos". Argumento legítimo y límite que, en las escuelas, deja a un número constante de alumnos marginados, solos y, a menudo, resentidos. Por lo mismo, favorece una discusión que enfrente nuestra libertad y nuestros derechos a otros valores, como la compasión y la solidaridad, Que se pregunten si existen maneras mejores de estar en el mundo, que todos puedan tomar la palabra y, si quieren, hablar de sus vidas, para que la narración los ponga fuera de ellos y sean motivo de interacción entre los niños.

Esta experiencia nos remite a la propuesta de Meirieu sobre la importancia de la transferencia en la escuela:

(...) restituir los saberes como respuestas a preguntas que se han hecho los hombres; como saberes movilizables por parte del que aprende para responder a preguntas que él mismo se hace o se hará. Es, luego, llevar al que aprende a que se proyecte mentalmente en el mundo cuando 
aprende, recuerde situaciones vividas, se represente o imagine situaciones a las que se enfrentará... (Meirieu, 1998, p.114)

Se trata de llevar a los niños a situarse por encima de la propia afectividad, desligarse de lo individual para que surja el espíritu de análisis que los vincula con los otros que reflexionan. (Tozzi, 2008)

\section{"prohibido parecerte a mí"}

Cierto que Peter Pan es simpático, inteligente y divertido, y que se preocupa por los demás... pero está centrado en sí mismo y en sus deseos. Le gusta tanto dar órdenes que a veces es autoritario y déspota, como lo revelan algunas de sus reglas, que a continuación citamos:

“Peter Pan arroja fuera de la isla a los niños cuando parecen empezar a crecer, lo que está en contra del reglamento" (Barrie, 2002, p.57).

“Únicamente en ausencia de Peter Pan podían los niños hablar de sus madres, pues Peter Pan había prohibido hablar de este tema por considerarlo tonto." (Barrie, 2002, p.61)

"Les tiene terminantemente prohibido parecerse a él en lo más mínimo." (Barrie, 2002, p.57)

Dado que el tema que se pretendía analizar con los alumnos eran las relaciones entre los niños, entre los líderes y los seguidores, no nos detuvimos a analizar el contenido de estas reglas. Un debate con estudiantes mayores nos hubiera permitido asomarnos, así fuera de manera superficial al inconsciente de Peter Pan, a las ausencias que lo habían marcado -si había tenido una madre, sólo recordaba sus malas cualidades- y a esa mezcla de temor y desprecio que le inspiraba la edad adulta; también hubiéramos podido analizar lo contradictorio de sus -nuestros- deseos: que lo imiten pero que no se parezcan a él. En esta experiencia el énfasis estuvo puesto en la arbitrariedad de las reglas: todos convenían en que eran absurdas y en que Peter las imponía para sentirse importante. A lo largo de la reflexión, algunos descubrían como algo nuevo que la función de las reglas es precisamente ayudar a un grupo a funcionar mejor, no hacer sentir bien a una persona. 
peter pan: el líder y sus seguidores. una experiencia de filosofía con niños

En cuanto a la sumisión de los niños a estas reglas absurdas, la mayoría estaba de acuerdo en que para pertenecer a un grupo hay que obedecer. Algunos llegaban más lejos y afirmaban que en ocasiones incluso hay que correr riesgos si así lo exige el grupo. No obstante, era notoria la dificultad para pensar en términos colectivos: más bien tenían en mente la aceptación del líder". Por ello, a la pregunta "¿Qué pasaría si todos los del grupo decidieran desobedecer las reglas?" respondieron con frases ambiguas o graciosas: no parecía una verdadera opción. Eran pocos los que veían en ese acto la oportunidad para oponerse a las decisiones del líder; también eran pocos los que estaban dispuestos a jugarse en esas preguntas, pues los interpelaban de manera personal, ponían en duda sus elecciones, sus valores, su manera de vivir. Como afirma Kohan,

no se trata de hacer preguntas externas, objetivas, acerca de algo exterior a nosotros sino ponernos a nosotros mismos en cuestión, dejar que las preguntas, nuestras preguntas y las otras preguntas, las preguntas de nosotros y de los otros, atraviesen lo que pensamos $\mathrm{y}$ sentimos. (Álvarez, 2015, p.153)

\section{"el más tonto de todos"}

En El País de Nunca Jamás, los niños obedientes y sumisos muestran otro rostro cuando sienten que pueden perder a Wendy, quien ha sido como una madre para ellos: está dispuesta a llevarse a sus hermanos de vuelta a casa y a separarse de los niños perdidos para siempre. La reacción de éstos es violenta: no le permitirán marcharse. Uno propone hacerla prisionera; otro, encadenarla. Sólo Lelo, el más tonto de todos, saca su espada y decide defenderla, exigiendo al resto de los niños que se porten como "caballeros británicos".

En el debate, a la mayoría de los alumnos les perturba la acción violenta de los niños contra Wendy, pero no les sorprende su egoísmo, ni el hecho de que quieran

\footnotetext{
${ }^{5}$ Es difícil saber en qué medida influyó el miedo en estas respuestas. Para B. Defrance es la causa del silencio de las víctimas en la escuela, aunque ésta no puede abdicar de su responsabilidad: "Si, en el día a día de la clase o del centro, la fuerza y la ley se mantienen confundidas (sean cuales fueren las formas que adopte el ejercicio de esta fuerza: autoritarismo o seducción), podemos comprender que la víctima se someta a sus verdugos, por el mismo movimiento psicológico que le hace someterse a la arbitrariedad "natural" del adulto, a la "ley del más fuerte"."(Defrance, 2005, p. 66)
} 
retenerla por sus propias necesidades; entienden también, aunque no compartan su postura, que el orgullo de Peter Pan le impida pedirle que se quede. A lo largo de la novela lo han conocido y saben lo que pueden esperar de él. El tema que sí desencadena discusiones entre los alumnos es el siguiente: si una sola persona se da cuenta de que el grupo está tomando una mala decisión, ¿tiene que hacérselo ver? ¿Es su responsabilidad? Nuevamente, la idea de oponerse individualmente al grupo corriendo el riesgo de suscitar su rechazo provoca temor, en una edad en que la identificación con los pares es básica en la construcción de la personalidad. ¿Cómo estar seguros de que se tiene la razón para atreverse a enfrentar una decisión que los demás consideran oportuna? Tal vez no somos lo suficientemente astutos, osados o inteligentes para elegir esa opción. Tal vez lo importante no sea la decisión, sino la adhesión, el hecho de sumarse a la "voluntad popular", pues las actitudes "separatistas", individualistas -a decir de los niños-, no suelen ser bien recibidas en los grupos. En todo caso, la pregunta respecto a si debemos oponernos al grupo a pesar de estar solos en nuestra convicción, tomando en cuenta los riesgos que implica, es un dilema que, como los otros, les genera conflictos, mismos que se expresaron en los debates.

Todos los debates generados en esta experiencia a partir del texto de Barrie rozan lo moral o lo abordan de lleno. Los dilemas morales han mostrado su potencial para el desarrollo del pensamiento crítico y, en esta línea, para el desarrollo moral (Kohlberg, Power y Higgins, 1997). Lo que los vuelve interesantes es la falta de solución, de respuesta acertada. Ninguna propuesta puede ser calificada de buena o mala, en todo caso se puede analizar su pertinencia a partir de las posibles consecuencias que implica. Esto garantiza un debate que supera lo dicotómico y abre la posibilidad a un número indeterminado de propuestas y a una profundización y complejización del asunto planteado. 
peter pan: el líder y sus seguidores. una experiencia de filosofía con niños

\section{de la ficción a la escuela}

El diálogo que entablamos con Peter Pan giraba, como hemos visto, en torno al tema de las relaciones entre pares. Nuestro propósito era preguntarle al texto sobre la naturaleza de estas relaciones, la violencia que encierran, los dilemas éticos que resultan, las distintas posturas que se pueden tomar frente a ellas y otras preguntas que flotaban en los pasillos de la escuela. Elegimos la novela Peter Pan porque cubría los siguientes requisitos:

1) es un interlocutor creativo y sensible

2) refleja un conocimiento del alma de los niños

3) tiene la suficiente profundidad para resistir un análisis crítico

4) las situaciones que plantea son transferibles a la vida cotidiana de los alumnos

No nos detendremos en las dos primeras cualidades que se refieren más a las virtudes del autor que a la obra, aunque son indispensables. En cambio, nos gustaría hacer hincapié en la importancia de que los argumentos planteados por los personajes de un libro infantil y los personajes mismos resistan un análisis crítico por parte de los lectores, es decir, que tengan un cierto espesor. Cuando Wendy llama a Lelo (Desdentado), "el más tonto de todos”, a defenderla, el comentario, casi al pasar, del narrador es "el instinto le dijo a Wendy a quién debía volverse" (Barrie, 2002, p.120): con ese comentario estamos aprendiendo una lección acerca de cómo se sienten los débiles cuando alguien les otorga fuerza y cómo, de pronto, adquieren poder. Gracias a ello, Lelo da un giro a la historia. Sólo los grandes escritores son capaces de hacer tanto en menos de una línea.

El otro requisito para lograr un diálogo filosófico a partir de textos literarios es que las situaciones que presentan sean extrapolables al contexto de los alumnos. Es en la escuela donde los niños aprenden a socializar y a relacionarse con sus pares; suelen hacerlo en pequeños grupos donde se dan relaciones de fuerza, y es común que uno se imponga de manera amigable o con cierta violencia a otros. En ese sentido, las situaciones que nos presenta Peter Pan son completamente verosímiles y transferibles a la cotidianeidad de los alumnos, a tal grado que éstos se identifican con los personajes 
-líder o seguidores- y llegan a sentirse agraviados por las opiniones que los demás alumnos expresan sobre su forma de actuar.

Un elemento clave en este trabajo es la reflexión grupal que permite a los alumnos expresar sus ideas y los obliga a enfrentarlas con las opiniones de sus compañeros, defenderlas, revisarlas y, en ocasiones, modificarlas. El debate libre, en el que la intervención del docente se limita a asegurar que los niños participen sin faltarse al respeto, a plantear preguntas cuando decae el intercambio, es una vía privilegiada para la reflexión: los alumnos se involucran en el debate por interés propio y se motivan unos a otros: algunos porque han identificado una situación que los concierne, otros por el placer de demostrar que tienen la razón.

\section{preguntas sin respuestas}

“No es fácil saber qué preguntas hacer, cuándo hacerlas y cómo hacer la pregunta apropiada" (M. Lipman, A. M. Sharp y F.S. Oscayan, 1992, p.186). Esta adaptación de Peter Pan para convertirlo en material para filosofar con los niños pone en el centro de la reflexión la pregunta y supone en los docentes la capacidad para preguntar-se, que implica flexibilidad, creatividad, reconocimiento de la propia ignorancia y también abandonar el lugar de la autoridad que posee y administra el saber. También exige tener conciencia de los propios límites, reconocer que las verdades son provisionales y que a menudo su fecha de caducidad está inscrita en la siguiente pregunta.

Las preguntas que aparecen en este material son una guía que el docente puede utilizar y ampliar. El desafío para cada uno es, entonces, aprender a preguntar. Construir preguntas que no tengan respuestas rápidas, más aún: que no tengan respuestas, que haya que inventarlas. Sólo las preguntas sin respuesta tienen valor educativo porque no implican adivinar lo que está en la mente del profesor, sino construir una realidad con los recursos que nos vamos procurando.

Con estos criterios elaboramos el material: preguntas que no sólo admiten múltiples respuestas, sino que éstas pueden ser cuestionadas y rebatidas por los 
peter pan: el líder y sus seguidores. una experiencia de filosofía con niños

mismos alumnos, porque se admiten diversas formas de interpretar la realidad y diversas jerarquías morales. Rebatiéndose, los alumnos aprenden a pensar, y cuando los argumentos que refutan son éticos, están aprendiendo a pensar éticamente: a ponerse en el lugar de los otros, a pensar en las consecuencias de los actos para cada uno de los involucrados, a pensar no sólo en términos prácticos, sino en términos de “bien” y “mal”. A la pregunta, ¿Por qué Peter Pan les pega a los niños en los nudillos?, los alumnos podrían responder: "Por no representar bien su papel de estar satisfechos con la comida", pero la pregunta "¿Tiene derecho Peter Pan a pegarles en los nudillos?" demanda otras respuestas, al igual que “¿Por qué los niños permiten que les pegue?”.

Otra dimensión fundamental de la pregunta es su carácter social: la pregunta interpela, llama al otro, lo reconoce como su semejante o como poseedor de algo de lo que él mismo carece. Es impensable una persona que se pregunta y se responde a sí misma: se apela no sólo a los conocimientos del otro, sino también a su mirada, incluso a su afecto. Preguntar es una forma de socializar y cuando los alumnos lo descubren, han adquirido un nuevo recurso para establecer vínculos.

Si creemos que la escuela es el lugar donde se forma la persona humana, no sólo en su capacidad crítica sino en su desarrollo moral, tiene que transformarse a sí misma para convertirse en un espacio donde sean posibles el libre examen y el debate. Sin embargo, para esto no basta con acostumbrarse a plantear preguntas sobre la materia prima que brinda la escuela, es necesario que los alumnos aprendan a observar, a analizar, a problematizar su propia vida, sus relaciones con los demás, su entorno, sus condiciones de trabajo, sus elecciones. Las problemáticas que las autoridades observan al interior de la escuela -los problemas de convivencia, de adicciones, de bullying, de depresión- no son problemas acerca de los alumnos, sino problemas de los alumnos que hay que discutir con ellos, pues sólo ellos podrán resolverlos. No se trata de escuchar sus opiniones para tomarlas en cuenta, sino de abrir los espacios para que ellos se escuchen, ayudarlos a formular las preguntas adecuadas para reflexionar y tomar posturas, habilitarlos para el diálogo filosófico y para que se hagan cargo de su 
situación. Que se conviertan en niños expulsados de Nunca Jamás porque están creciendo.

Es urgente que los propios alumnos asuman la tarea de construir el mundo y que cuenten con herramientas adecuadas. Consideramos que una puede ser el texto de Barrie, que diseña un mundo de fantasía para reproducir en él las relaciones que se dan en el mundo real: relaciones complejas en las que pesan el pasado, las expectativas y la cultura de cada individuo; relaciones que reflejan las carencias y las ambiciones humanas y que, por lo mismo, presentan personajes imperfectos con los que el lector puede identificarse sin temor.

Son pocos los espacios que se les otorgan a los alumnos de primaria para debatir porque la urgencia de terminar los programas cancela todas las buenas intenciones de los docentes y, con ello, la tarea de desarrollar la reflexión en los estudiantes. Los debates son insustituibles porque su objetivo es prioritario en la educación: la problematización del mundo. En esta experiencia se combinó lo lúdico con lo serio, lo cotidiano con lo profundo, Peter Pan -una historia que los niños asocian con el juego y con la fantasía- sirvió para que ellos pensaran por sí solos, sin que nadie dictara la norma, y se dieran cuenta de que son capaces de pensamientos profundos. Permitió que, por un rato, el mundo perdiera su transparencia: dejó de ser un dato para convertirse en un problema, un interrogante que abre paso a muchos otros. Un juego intelectual que aleja a los niños de la conversación superficial y los lleva a confiar en el pensamiento. 
sobre la experiencia

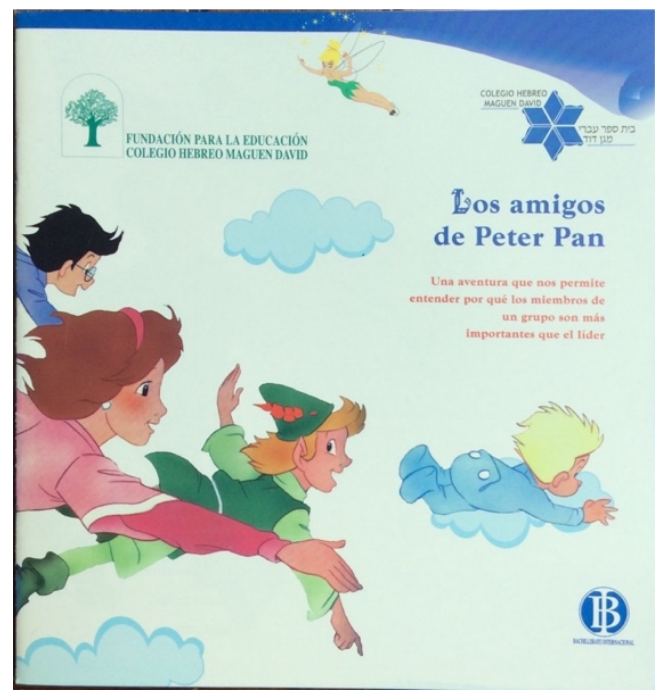

Esta experiencia de filosofía con niños a partir de cuentos clásicos se realizó con el apoyo de la Fundación para la Educación del Colegio Hebreo Maguén David, en dicho colegio (CHMD), durante los años 2002 a 2008, con los alumnos de los seis grados de primaria. Cada año elegimos un cuento clásico ${ }^{6}$ que los niños conozcan por haber tenido contacto con él a través de un libro o de una película. Aunque hubo variaciones en cada una de las experiencias, resumimos aquí lo que tuvieron en común.

Primera etapa: Selección e investigación

Lectura de libros infantiles y de algunos trabajos sobre ellos: investigaciones, propuestas metodológicas o programas universitarios. La elección del tema responde a alguna problemática de la escuela señalada por los directivos. Después de una lectura profunda y de un análisis del libro que nos permita tener una idea global para adaptarlo a nuestro objetivo, releemos el libro en busca de pasajes que susciten en los niños un cuestionamiento de sus propias posturas -con frecuencia, reforzadas por el contexto- respecto al tema abordado.

Con el esbozo del trabajo en mano, procedemos al diálogo, a "rebotar las ideas", trabajando al alimón con una experta en evaluación y planificación, Malvina Szpiro, y

${ }^{6}$ Menos en el 2008 en el que se unieron cuatro en un mismo tema: El patito feo, Blancanieves, Cenicienta y Harry Potter. 
con una socióloga y conceptualizadora de experiencias interactivas, Leticia Gorostieta, además de la coordinadora, que trabaja en las áreas de educación no formal y de ética. Con su colaboración, traducimos a "lenguaje niño" los conceptos, ubicamos problemas que les resulten familiares y formulamos preguntas disruptivas para realizar una encuesta entre los niños de la misma institución con el fin de conocer sus puntos de vista sobre los problemas que serán el eje de nuestro trabajo.

Segunda etapa: Elaboración de los materiales

a. Elaboración del contenido: Con la información obtenida, escribimos los textos con la siguiente estructura:

-Síntesis del cuento y comentarios para despertar el interés de los alumnos -Contexto del tema a partir de ilustraciones y citas textuales.

-Análisis de los personajes

-Preguntas provocadoras derivadas del cuento

-Actividades y juegos desafiantes

-Reflexiones a partir del pensamiento creativo de los niños

b. Diseño: En colaboración con el departamento de diseño del CHMD, se deciden los elementos gráficos adecuados para detonar el debate. El producto, en todos los casos, son lonas plastificadas de aproximadamente dos metros cuadrados y un libro con el mismo contenido e imágenes. Las lonas se cuelgan en los muros de la escuela donde permanecerán algunos meses: la idea es sacar del aula los debates sobre cuestiones éticas y ponerlos en el centro de la vida escolar. Los alumnos tienen la oportunidad de volver una y otra vez sobre las cuestiones que les interesan. Los libros son distribuidos a todos los alumnos y visitantes.

c. Los títulos y temas de las exposiciones son los siguientes:

- Diálogos en el país de las maravillas: la importancia del diálogo y la resolución de conflictos. (2002)

- El Espacio del Principito: las relaciones humanas, la convivencia, el individualismo. (2003)

- Las Fantasías de Pinocho: el aprendizaje de ser niño. (2004)

- $\quad$ El camino de Oz: el autoconocimiento y la solidaridad. (2005) 
peter pan: el líder y sus seguidores. una experiencia de filosofía con niños

- Los amigos de Peter Pan: las relaciones entre pares. (2006)

- La ley de la selva: las normas de convivencia. (2007)

- $\quad$ Ni patitos, ni feos: las actitudes ante el "diferente". (2008)

Tercera etapa: Aplicación con los alumnos

La experiencia se realiza con niños de todos los niveles de primaria, guiados por un docente capacitado que provoca la reflexión y conduce el diálogo y el posible debate. El objetivo es que los participantes revisen sus vivencias, expongan sus supuestos, sus miedos y sus preocupaciones para confrontarlos con los del resto del grupo y logre construir sus propias conclusiones.

Consiste en distintos momentos:

1. Trabajo con los docentes. Inicia desde la elaboración, pero cuando están listos los libros, se analizan para que todos planteen las preguntas y posibilidades que identifican para abordar situaciones de conflicto en la vida escolar. Cada uno elige las escenas en las que quiere hacer hincapié.

2. Los docentes eligen la forma de introducir a sus alumnos: lectura o narración del cuento, contextualizar el material elaborado y conversar sobre éste u otras actividades más lúdicas. Posteriormente cada maestro, en el horario que se le asignó, va con alumnos a hacer un recorrido por la exposición. Los niños se sientan en el piso y el docente provoca y guía el debate; puede solicitar más tiempo o un segundo horario de recorrido. Al volver a clase, realiza las actividades que diseñó previamente.

\section{Cuarta etapa: Extensión}

1. Comunidad educativa: Se decide hacer extensivos los recorridos por las exposiciones a toda la comunidad educativa: padres, docentes de otros niveles, personal administrativo y de mantenimiento, chóferes y personal de vigilancia. Sorprende que las mismas preguntas formuladas para los niños -contextualizadas en mundos adultos- les resultan significativas. Los debates suelen ser interesantes.

2. Visitantes: Se invita a niños y docentes de otras escuelas de la zona, así como a personas de distintas instituciones. Personas del colegio fungen como guías y promueven el debate. Cada año se reciben alrededor de 400 visitantes: alumnos de 
escuelas privadas y públicas, funcionarios, docentes, miembros de comités comunitarios y público en general. En cada exposición se crea un libro de visitas para recoger las impresiones de los asistentes.

3. Otros espacios: Uno de los propósitos de este trabajo es compartirlo con otras instituciones, por lo que las exposiciones fueron presentadas en diversas escuelas particulares y públicas, urbanas y rurales, en la Secretaría de la Función Pública, en la Casa del Árbol de la Comisión de Derechos Humanos del Distrito Federal, en todos los Colegios de Ciencias y Humanidades de la Universidad Nacional Autónoma de México, en organizaciones de la sociedad civil y en instituciones comunitarias.

\section{Quinta etapa: Evaluación cualitativa de la experiencia}

Se realizan evaluaciones cualitativas cuyas fuentes de información son:

-Recopilación de los comentarios de los alumnos por parte de los maestros

-Comentarios y sugerencias de los docentes

-Libro de visitas

Los informantes clave son los alumnos -de la escuela y de otras escuelas-, los docentes -de la escuela y de otras escuelas- y los padres de familia, y las autoridades. Al concluir el periodo de trabajo sobre la exposición, el equipo coordinador se reúne para comentar los resultados que son tomados como base para la siguiente exposición.

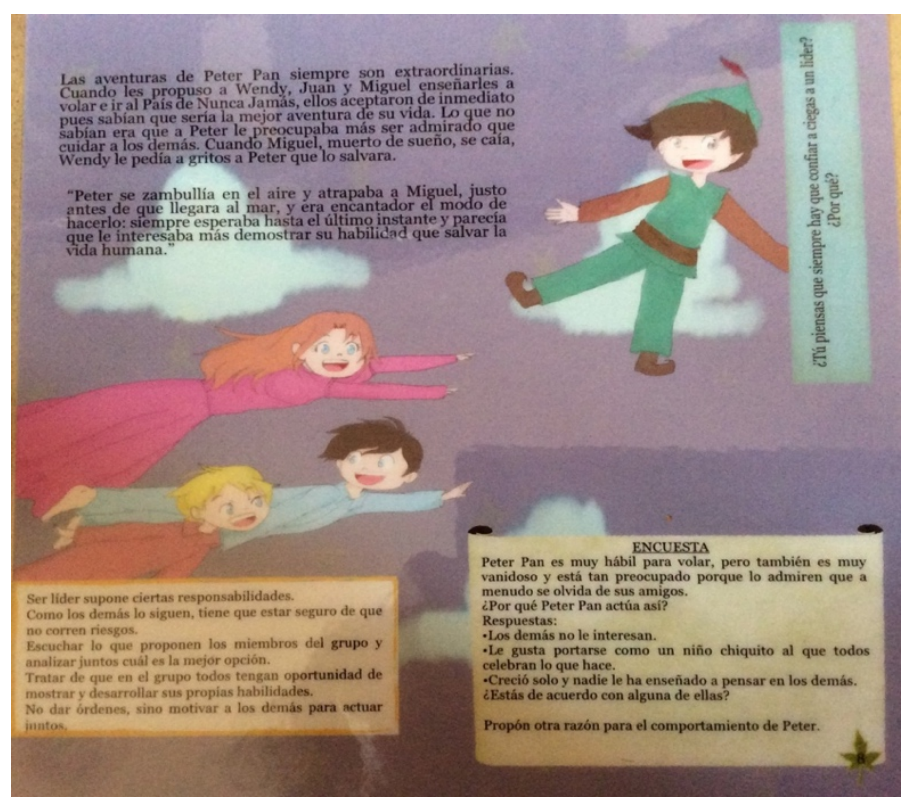


peter pan: el líder y sus seguidores. una experiencia de filosofía con niños

\section{en suma...}

La realización de estas exposiciones ha requerido una investigación minuciosa sobre los autores, el contexto histórico, la utilización que se ha hecho de las historias en el cine, el teatro, la televisión, el arte y las aulas. ${ }^{7}$ Esto nos ha habilitado para ofrecer a los maestros una mirada más compleja, que permite lecturas distintas y manejos originales, y opciones para filosofar con niños, pues éstos están ávidos de pensar su propia vida.

Entre los hallazgos derivados de la experiencia, mencionaremos los más significativos para nosotros:

Comprobamos que las obras literarias pueden servir como detonador para la reflexión y el debate. Los alumnos, guiados por los docentes, lograron apropiarse de las preguntas planteadas en el contexto de la novela, hacer un puente y darles respuesta desde sus vivencias personales. Además, se enfrentaron a cuestionamientos sobre las relaciones entre pares y argumentaron su postura; escuchar los comentarios de sus compañeros los animó a involucrarse. Trabajar fuera del aula parece haber propiciado un clima relajado que contribuyó a la participación de los alumnos. La construcción de "un espacio seguro" (Meirieu, 1998, p.82) permitió que se expresaran sin miedo a ser ofendidos por sus compañeros.

Por otro lado, descubrimos que un material basado en preguntas problematizadoras funciona en los seis niveles de primaria y convoca también a los adultos, quienes intervienen desde sus propias experiencias. En cambio, los estudiantes de bachillerato se rehusaron a participar, por considerar que el material era muy infantil.

El recurso humano es un área de intervención y mejora debido a las resistencias de los docentes, que no están familiarizados con el pensamiento crítico. Les resulta difícil abandonar las prácticas tradicionales y les faltan herramientas para hacer intervenciones disruptivas que estimulen el pensamiento crítico en los niños, alejadas de las preguntas que demandan respuestas mecánicas. También les costó trabajo

\footnotetext{
${ }^{7} \mathrm{Y}$ nos ha mostrado que no todos los textos ofrecen la posibilidad del trabajo aquí descrito
} 
desprenderse del cuento y no asumir una actitud moralizadora. Sólo algunos maestros ayudaron a los niños a problematizar la realidad, y no tomaron las riendas de la discusión.

El ejercicio realizado logró instaurar durante varios ciclos escolares una tradición que era esperada año con año en el CHMD y que trascendió sus muros y benefició a otros destinatarios, lo que nos ratificó que la filosofía con niños es posible y que la articulación pedagogía-filosofía-literatura, la enriquece.

Las exposiciones didácticas no son un trabajo terminado, sino que abren una veta interdisciplinaria en la que pueden articularse el placer y la duda. Esta metodología de trabajo es replicable y podría convocar a los profesionales de la filosofía y la pedagogía para trabajar en conjunto con los docentes de cualquier nivel educativo, de manera que éstos se formen en los métodos del razonamiento filosófico.

En una época en que muchos gobiernos se obstinan en aniquilar la filosofía, ésta podría ser una de las puertas de entrada a la formación escolar.

\section{bibliografía}

AGRATTI, L.V. (2016) “La práctica de la filosofía en la educación y el propósito de que cada vez sean más los que se representen el mundo como propio". En: KOHAN, W.O., LOPES S. y MARTINS, F. (orgs.) O ato de educar em uma lingua ainda por ser escrita, Rio de Janeiro: Nefi.

ÁLVAREZ, J.P (2015) “No hay quien pueda pensar por otro". Entrevista a Walter O. Kohan. En: J. E. Pérez, J.P. Álvarez y C. Guerra Eds.), Hacer filosofía con niños y niñas. Entre educación y filosofía. Valparaíso: Universidad de Valparaíso.

BARRIE, J, M. (2002). Peter Pan. Barcelona, España: José J. de Olañeta. Ed.

CHARABATI, E. (2006). Los amigos de Peter Pan. México: Fundación para la Educación Colegio Hebreo Maguén David.

DEFRANCE, B. (2005): Disciplina en la escuela, España, Ed. Morata.

HAWKEN, J. (2016). Philosopher avec les enfants : enquête théorique et expérimentale sur une pratique de l'ouverture d'esprit [Filosofar con los niños: encuesta teórica y experimental sobre una práctica e la apertura de espíritu] (Tesis doctoral). Paris: Université Panthéon-Sorbonne, Paris.

KOHLBERG, L., POWER, F. y HIGGINS, A. (1997). La educación moral. España: Gedisa.

LIPMAN, M, SHARP, A.M. y OSCAYAN, F.S. (1992). La filosofía en el aula. Madrid: Ediciones de la Torre.

MAULINI, Olivier (1998). “La question: un universel mal partagé”, en: Educateur, n7, p.13-20. Recuperado de: <https://archive-ouverte.unige.ch/unige:35542>

MAULINI, O. (2005). Questionner pour enseigner $\mathcal{E}$ pour apprendre. Le rapport au savoir dans la classe. Paris: esf. 
peter pan: el líder y sus seguidores. una experiencia de filosofía con niños

SKLIAR, C. (2017). Pedagogías de las diferencias. Bs. AS: Noveduc.

TOZZI, M. (1999). Apprendre a philosopher au cours de morale, Bruxelles: Entre-vues.

TOZZI, M. (2008). Pensar por sí mismo: iniciación a la pedagogía de la filosofía. Madrid: Editorial Popular.

recibido: 05.04.2019

aprobado: 12.05 .2019 